\title{
BLAST PROTECTION WALL SYSTEMS: LITERATURE REVIEW
}

\author{
ASSAL T. HUSSEIN \\ Civil Engineering Department, University of Diyala, Iraq
}

\begin{abstract}
This paper presents a review of the current research trend to design blast protection wall systems. The paper summarizes the published research of the high-tech composite blast wall systems made of advanced materials. The summary includes system components and material properties, design philosophy, parametric study, system performance, and limitations of such type of blast-resistant systems. The level of terrorist attack threats has increased significantly in the last few years, especially in the Middle East targeting populated areas and leaving numerous victims and billions of dollars' worth of losses in infrastructure. Therefore, the use of high-tech blast-resistant wall systems might be hindered by its lack of available materials and construction technology in most countries. Primitive protection systems to guard from surrounding risks, whether natural or man-made have been used for temporary and military fortifications. The simple protection systems could provide the required safety level with minimal efforts and low cost. This paper highlights the research gap in considering simple blast protection walls made of readily available materials to mitigate blast. This paper also discusses the recent research attempts to investigate the performance of blast walls made of thin timber sheets and plain sand as an example of low-tech materials for permanent applications. The study clarifies the efficiency of simple blast wall systems to attenuate blast based on the open-space blast test measurements and numerical analysis results. However, simple blast wall systems may not be appropriate to install in urban areas yet, hence, future studies are invited to conduct integrated studies to investigate and implement architecture design modifications for this purpose.
\end{abstract}

Keywords: terrorist attacks, temporary blast protection techniques, high-tech blast wall systems, simple blast wall systems, low-tech materials.

\section{INTRODUCTION}

Suicide attacks are strange and unique phenomenon which have been hindering the communities' development and, in some cases, threatening their existence. This threat is no longer a local problem but has become a global issue, which mandates collaboration between countries to overcome this danger. The attacks can occur anytime and anywhere based on the goals from these attacks. These bombings, typically caused by terrorist attacks, have left substantial losses due to complexity in nature and dynamism goals of these attacks [1]. The blast shock wave from high explosives detonation has a very sharp acting on unprotected people and targeted structures due to high applied pressure. The duration of blast shock wave is very short, typically in order of $10^{-6}$ seconds for near-field blast and milliseconds for farfield detonation. The intensity of blast depends on the explosive weight, standoff distance and pressure amplitude of blast wave. Long and short term effects can be noticed on people when exposure directly to the blast. Several studies have investigated and analysed these effects [2]-[4], but such effects are outside the bounds of the present study. Accordingly, consideration of an appropriate blast-resistant system is required to reduce causalities and losses.

Only federal facilities, military bases, and important governmental buildings had been designed to resist abnormal loadings such as blast due to the high cost, the applicability of fortification, and the importance level of the structure. Furthermore, it is not an available option for engineers to strengthen existing residential and commercial buildings to resist 
large-scale detonations [5], [6]. Therefore, constructing a blast protection wall at an appropriate distance (safe zone) from structures can provide the required level of safety for occupants and property behind/around the blast wall [7], [8]. The blast wall could reflect and/or absorb the blast wave energy by the mass of the system, and energy absorbing mechanism. Fracture or permanent deformation is possible when the applied pressure is higher than the capability of the system to resist the incident/reflected blast wave. In both cases, a blast wall could attenuate the blast and protect targeted structures and people.

The main objective of perimeter protection systems is to increase the standoff distance between people and assets, and explosion source [5]. This strategy has been considered for structures that do not have the capability to resist blast loading [9]. Several methods can be used to ensure maximum distance between the targeted structure and location of explosion source such as anti-ram decks, speed reducing bumpers, traffic control techniques, and walls. Safe standoff distance can be determined based on the size of the explosive charge, standoff distance, and explosion scenario. For instance, the U.S. Department of Defense (DOD) listed safe evacuation distances of unreinforced concrete structures in free space as shown in Table 1.

Table 1: Safe evacuation distances of different attack scenarios [9].

\begin{tabular}{|l|c|c|c|}
\hline Attack scenario & $\begin{array}{c}\text { TNT equivalent } \\
\text { mass }(\mathrm{kg})\end{array}$ & $\begin{array}{c}\text { Building evacuation } \\
\text { distance }(\mathrm{m})\end{array}$ & $\begin{array}{c}\text { Outdoor evacuation } \\
\text { distance }(\mathrm{m})\end{array}$ \\
\hline Belt & 4.5 & 27 & 330 \\
\hline Suicide vest & 9.0 & 34 & 415 \\
\hline Suitcase bomb & 23.0 & 46 & 564 \\
\hline Compact car & 227 & 98 & 457 \\
\hline Water truck & 13,608 & 375 & 1,982 \\
\hline Semi-trailer & 27,216 & 475 & 2,134 \\
\hline
\end{tabular}

A classical protection method has been adopted by placing reinforced concrete (RC) blocks around military and security facilities, and other targeted areas. This approach had also been used extensively after 2003 in the Republic of Iraq to restrict traffic flow inside cities. This trend was required due to the size of threat and time constraints to find alternatives, but some arguments have been established about the impacts on community lifestyle, limitations in using RC walls to protect civilians, and high cost of establishing such type of blast walls. For instance, this protective strategy has left significant effects on community life in Iraq. The Iraqi cities have lost their cultural and architectural identities, existence of these blocks has created a state of depression inside the community. Mobility within and between cities has become difficult and requires relatively long time and effort since only specific entries and exits points can be used. The cost associated with constructing these walls adds another burden to the communities. For instance, to construct $21 \mathrm{~km}$ of T-wall needs 4,000 units, and the total cost will be 12.5 million dollars [10].

The current research trend is to design composite sandwich panels to resist blast loading [11]-[17]. Several studies have been conducted to examine different types of high-tech blast wall/panel systems made of high-tech materials to mitigate blast loading. While evaluating the effectiveness of different types of blast protection wall systems using high-tech material is reasonable, since the objective is to mitigate the impact of the blast, the use of such materials and techniques might be hindered by lack of their availability in most countries. The question is: is it required to use such blast wall systems in all explosion scenarios? It is obvious that resisting blast load without visible damage is not required in most design cases, 
thus investigating the performance of simple blast wall systems to be used for permanent applications in different attack scenarios and site conditions is recommended to minimize the impact of terrorist attacks.

Simple blast wall systems, typically sandbags, plain sand, timber sheets, plain concrete and masonry walls have been used for military and temporary fortifications purposes. This approach is not totally new since people have considered primitive protection systems to protect themselves from surrounding risks whether they are natural or man-made hazards. Thereafter, with evolution and complexity of life, the need to use effective protection methods to reduce losses resulting from these risks have appeared. Therefore, conduct new research studies focused on designing simple blast wall systems made of readily available materials for permanent applications is urgently needed. This article highlights the research gap of designing blast wall systems since only high-tech systems have been considered so far and there is need to design realistic permanent blast wall systems for structural protection to be installed in urban areas and used by individuals against terrorist attacks. A full realization of the simple blast walls will have to be case-specific and will require a more integrated study in which the efficiency of the wall is assessed based on the height-to-width ratio, and thickness.

\section{HIGH-TECH COMPOSITE BLAST-RESISTANT WALL/PANEL SYSTEMS}

Blast-resistant systems have been designed considering high-tech materials. The current research trend is to design composite sandwich panel to resist blast loading. The need to use lightweight materials and strengthening existing structures is the current concerns of most studies. The composite sandwich blast-resistant systems composed of two face-sheets made of highly ductile materials such as high strength steel to resist/reflect incident blast shock wave. The core structure is made of highly compressible (low density) materials such as foams to absorb the blast shock wave. Fig. 1 shows typical components of the composite sandwich system. Several studies have been conducted to examine different types of hightech blast wall systems to mitigate blast loading. Most studies have focused on using sophisticated systems, and advanced materials. The studies have evaluated blast wall systems, which can be part of structures as a structural element to resist blast loading.

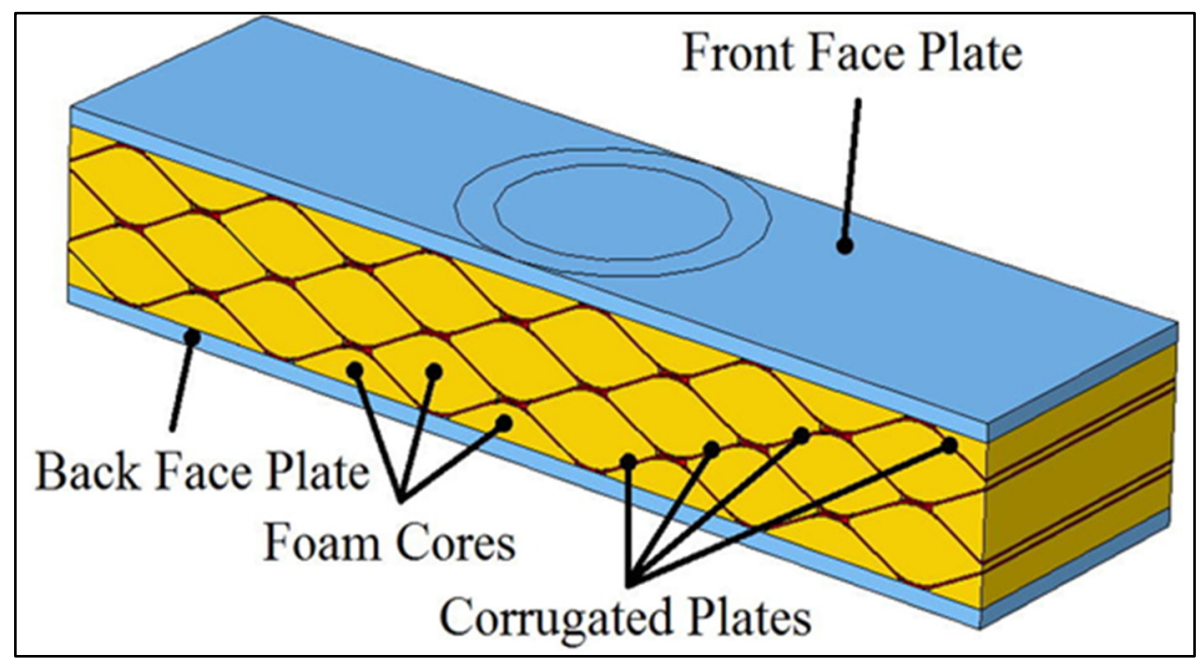

Figure 1: Blast-resistant sandwich panel components [18]. 
The design philosophy of such blast-resistant systems considered the front-face sheet as a reflector of the blast shock wave through the ductile behaviour and the core structure as an absorber of the kinetic energy of the blast shock wave. It was found that increasing the thickness of the front face sheet is important to increase the system performance. Moreover, increasing the thickness of the core web and angle of rippled core improves the crush resistance. The thickness of the core can impact negatively the local stiffness behaviour of the face-sheet despite improving the stiffness of the panel. This effect attributes to the local bending which is generated from the longitudinal pressure wave at the joint of the core layers. In conclusion, if the cover plate thickness was not designed properly to resist the applied pressure, non-uniform permanent deformation in the core structure will occur, in this case, part of the load will be carried by the panel itself leading to a system failure. The performance of composite sandwich blast panels has been examined [11]-[26]. Different geometries and types of sandwich panels have been considered such as flat, curved, stiffened and unstiffened, metallic, and non-metallic [16]-[19], [24]. The front-face sheet has been made of high-ductile materials such as high strength steel, hybrid composite steel sections, while core structure made of foams, polymers, metallic, functionally graded materials, and fiber reinforced polymer (FRP) [14], [24]. Several parameters were considered such as the thickness, density, layer height, number of horizontal layers and configuration of the core structure, thickness of the cover plate and interface interaction between the cover-plate and core structure. Matsagar [22], conducted a comparison study to examine the performance of different composite and non-composite sandwich panels under blast loading. The results of the numerical analyses represented the dynamic response of stiffened and unstiffened steel plate, plain concrete $(\mathrm{PC})$, reinforced concrete $(\mathrm{RC})$, and steel fiber reinforced concrete slabs (SFRC), stiffened and unstiffened steel-polyurethane foam-steel (SPC), steel-dytherm foam-steel (SDS), steel-cenosphere aluminium alloy syntactic foam-steel, and steel-sandsteel (SSS) sandwich panels. The author considered different parametric studies such as foam and sand layer thickness, stiffeners arrangements, panel thickness, and materials properties of sandwich panel. The considered of the composite sandwich panels, stiffeners configurations, and SDS composite panel model are shown in Fig. 2(a)-(c). Fig. 3 shows the central peak deformation of the SDS composite panel. The outcomes of the study concluded the following: stiffened panels with rectangular stiffeners configuration showed good capability to mitigate blast, SFRC panel mitigated blast wave energy effectively, composite sandwich panel made of cenosphere aluminium alloy syntactic foams experienced less deformation comparing to other panels made of other foam types. Hua et al. [24] investigated the performance of carbon fiber sandwich panel subjected to blast loading. Several blast tests were conducted to measure the response at the front and back center of the sandwich panels. Moreover, the blast wave-structure interaction was analysed numerically. It was noticed that peak reflected overpressure is 2.5 larger than peak overpressure of incident pressure. The numerical model was developed and validated with experiments results. The core foam showed higher contribution to dissipate blast wave energy comparing to front and back facesheets. The authors illustrated that core thickness, size of face-sheet are the most important design parameters to enhance sandwich panel to resist blast loading. Furthermore, the efficiency of the composite sandwich panels to resist blast was determined through the value of peak deformation of the back face-sheet. The geometry of the considered sandwich panel, finite element model, and peak deformation in the back face-sheet in terms of the front facesheet and core foam thicknesses are shown in Fig. 4(a)-(d), respectively. This paper summarizes the current approach of designing blast wall-resistant systems according to the reviewed literature as shown in Fig. 5. 


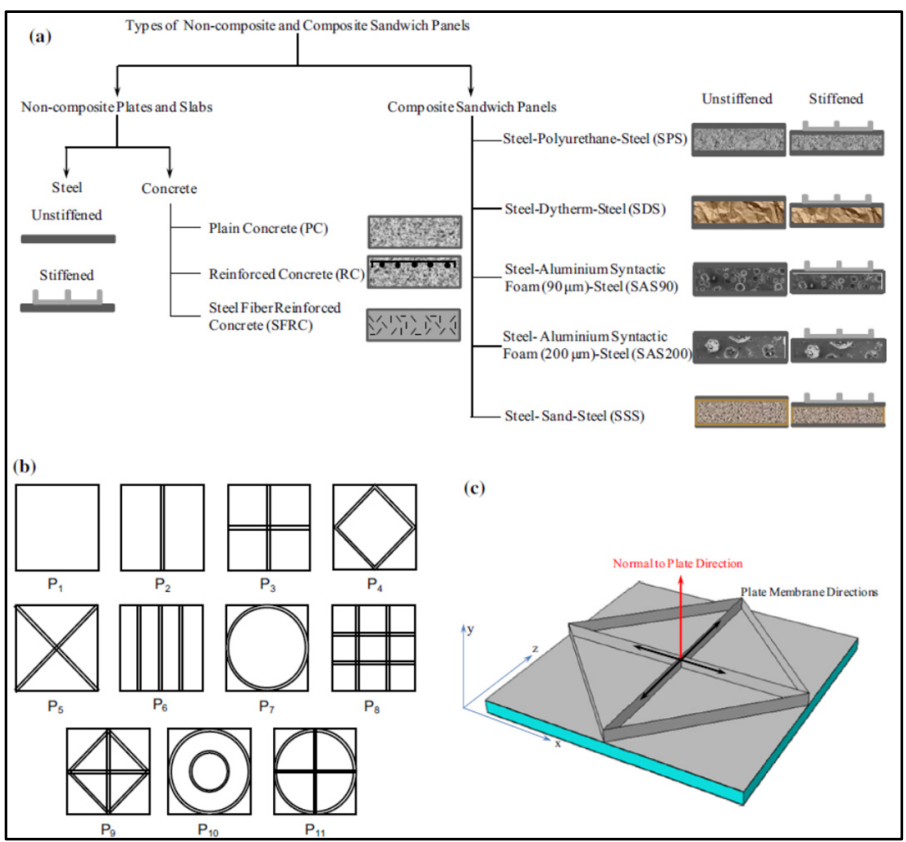

Figure 2: (a) Composite and non-composite sandwich panels; (b) Stiffeners configurations; and (c) FE model of stiffened composite sandwich panel [22].

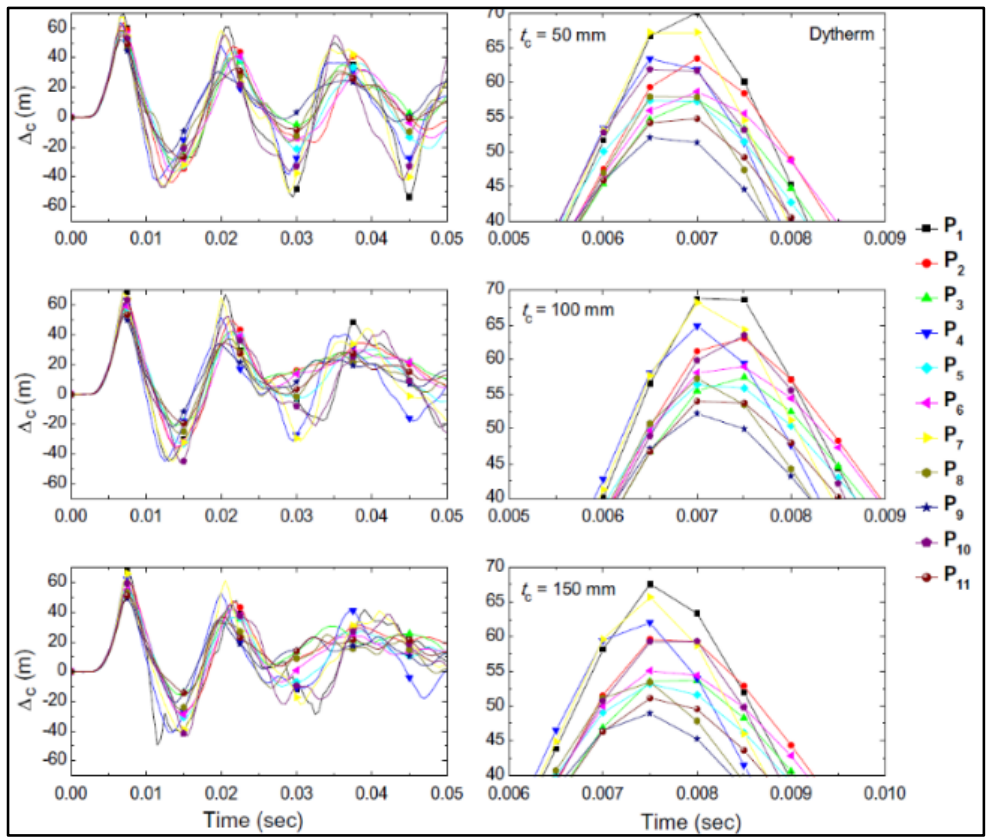

Figure 3: Central peak displacement of the SDS composite sandwich panel for different foam thicknesses [22]. 


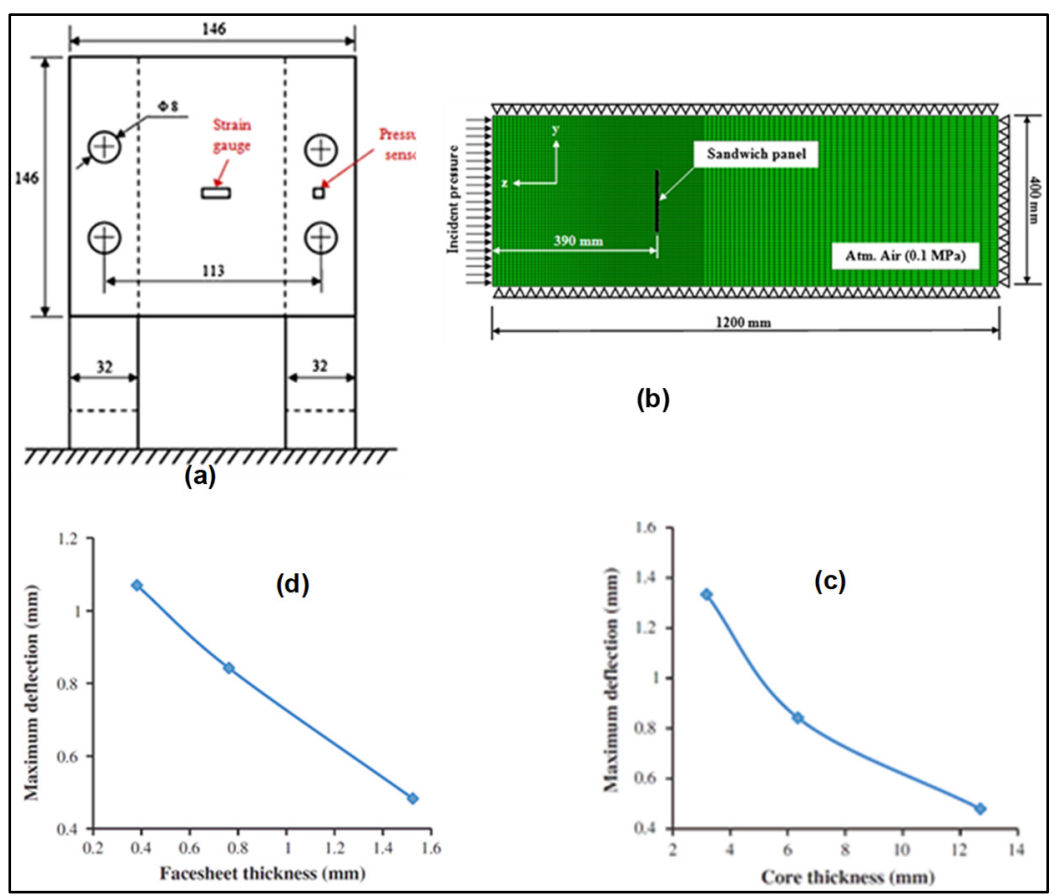

Figure 4: (a) Front view of sandwich panel; (b) FE model of sandwich panel; (c) The peak deformation of the back cover-plate based on (c) core thickness; and (d) frontplate thickness [24].

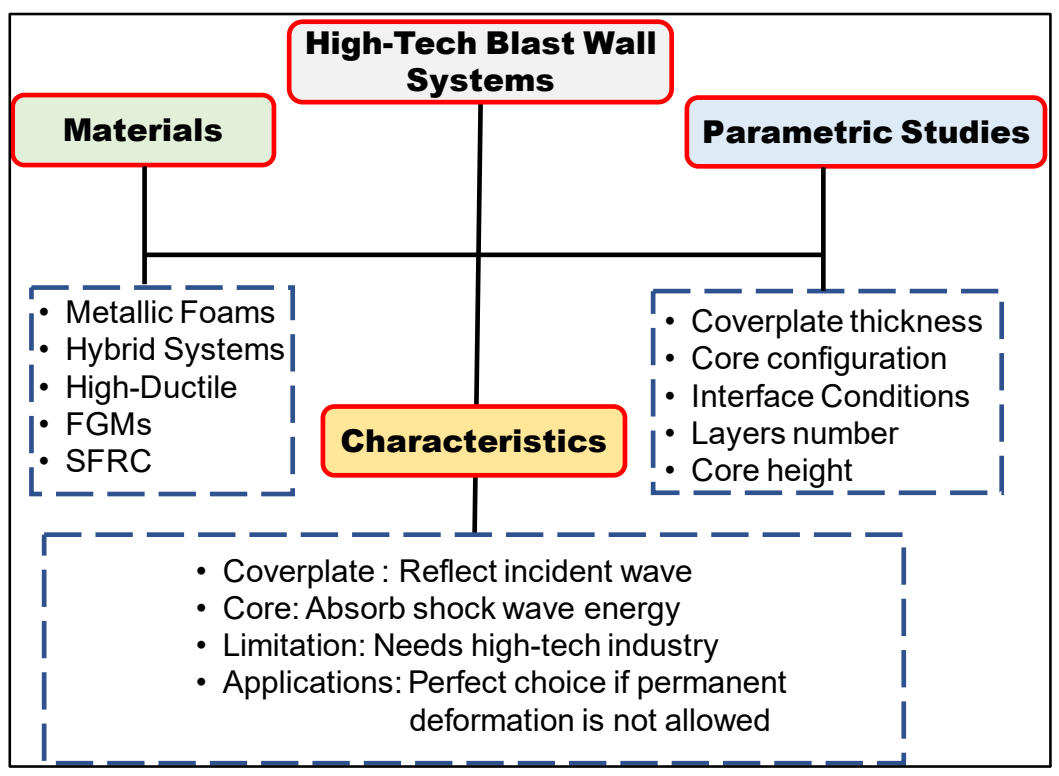

Figure 5: The current approach of designing high-tech blast wall systems. 
The composite sandwich blast panels have shown a good capability to mitigate highexplosive detonations of different blast scenarios based on published literature but with the increase of the cost. Therefore, the applications of such systems are limited and not applicable for residential houses and public facilities. However, it is recommended to consider such types of blast protection systems when permanent deformation is not permissible due to design specifications. Different approaches have been adopted to investigate the performance of the high-tech blast panel systems under blast loading. Comparison among different blastresistant systems in terms of components, analytical approach, and parametric study are illustrated in Table 2.

Table 2: Summary of composite sandwich blast panels conducted studies.

\begin{tabular}{|c|l|l|l|}
\hline Reference & Components & Approach & Parametric study \\
\hline 11 & $\begin{array}{l}\text { Core: honeycomb foam } \\
\text { Faceplate: Aluminum }\end{array}$ & FEM & $\begin{array}{l}\text { Faceplates and core } \\
\text { thicknesses and height }\end{array}$ \\
\hline 12 & $\begin{array}{l}\text { Core: foam } \\
\text { Faceplate: Carbon/epoxy }\end{array}$ & 2D-FEM & $\begin{array}{l}\text { Ductile interlayers } \\
\text { efficiency }\end{array}$ \\
\hline 13 & $\begin{array}{l}\text { Core: cellular metal } \\
\text { Faceplate: stainless steel }\end{array}$ & Test, FEM & $\begin{array}{l}\text { Front and back face-sheets } \\
\text { response, Core crushing } \\
\text { energy }\end{array}$ \\
\hline 16 & $\begin{array}{l}\text { Core: foam } \\
\text { Faceplate: steel, concrete }\end{array}$ & $\begin{array}{l}\text { Test, FEM, } \\
\text { Fare: graded foam }\end{array}$ & $\begin{array}{l}\text { Thermal insulation, blast } \\
\text { resistant, spall resistant }\end{array}$ \\
\hline 17 & $\begin{array}{l}\text { Fore: curved foam } \\
\text { Faceplate: }\end{array}$ & FEM & $\begin{array}{l}\text { Core crushing, core } \\
\text { deformation, core shape, } \\
\text { faceplate response }\end{array}$ \\
\hline 21 & $\begin{array}{l}\text { Stiffened and unstiffened } \\
\text { steel-foam-steel, steel- } \\
\text { sand-steel }\end{array}$ & FEM & $\begin{array}{l}\text { Radius-to-thickness ratio, } \\
\text { angular extent, foam core } \\
\text { thickness }\end{array}$ \\
\hline 24 & $\begin{array}{l}\text { Core: Aluminum foam } \\
\text { Faceplate: steel }\end{array}$ & $\begin{array}{l}\text { Team and sand layer } \\
\text { thickness, stiffeners } \\
\text { arrangements, thickness }\end{array}$ \\
\hline
\end{tabular}

\section{SIMPLE BLAST PROTECTION WALL SYSTEMS}

\subsection{Introduction and background}

Historically, low-tech materials had been used for different purposes and goals. Sand, wood, and rocks, and other available materials were used as protecting materials from numerous threats such as floods in addition to wide range of civil and military applications. In the middle ages, sand was used to fortify forts and cities since it provides a good level of protection from catapult strikes and exploded projectiles. Thereafter, during World War II, sandbags were used in different applications of protection, such as shielding windows, nonpermanent fortifications, soft armor for vehicle, and temporary blast walls. Sandbags have also been used to control floods and stabilize soil. Mechanically, sand has high compressive strength and low shear strength. The main advantage of using soil/sand as a core material in 
blast wall systems is the high capability of sand to dissipate the kinetic energy of the blast wave even for large-scale of explosive charges [27]. The attenuation level of sand is function of the layer thickness and density [28]. The response of structure under blast load is mitigated significantly by the mass of the structure since blast wave will be passed fast while the mass has not been mobilized yet [29]. Moreover, sand does not produce any debris, therefore would be no injuries from flying fragments. This is just about the sand other in hand materials could have the same capability but need to be investigated. The blast protection wall systems made of low-tech materials could be simple, but so effective. The system could be collapse totally or partially but provides the required level of safety [7]. Even though this type of blast wall system has some limitations: inappropriate to construct in crowded and/or urban areas, permanent deformation is not allowed in some structural systems, and absorption blast energy is based on mass inertia. But it is still important to consider in several cases especially when fund and time are limited to construct permanent facilities [8]. Some limited works had been done in the last century, but they were done for military purposes and temporary applications [7], [8], and the idea of considering simple blast wall systems for permanent applications had not been discussed. Recent applications of using sand in protection from suicide/bomb attacks are noted in the U.S. at different events by the security agencies and local police departments. For instance, the New York City Police Department (NYPD) used 82 sandfilled trucks to protect Macy's Thanksgiving Parade on November 23, 2016. Another example of using sand to protect from bombings, is the NYPD trucks filled with sand on November 8, 2016, around Trump Tower in Manhattan to mitigate any expected attacks. These attempts still temporary and cannot be considered for permanent applications.

\subsection{The efficiency of simple blast wall systems in mitigating blast loading}

Limited research has been conducted to investigate the performance of simple blast wall systems such as special reinforced concrete wall, high strength steel wall in addition to earthfilled and low-tech barriers [7], [8], [30], [31]. The studies focused on measuring the blast wave parameters such as peak overpressure, impulse, and duration. The studies showed that size and type of charge, standoff distance, height and geometry of the wall are the main factors to identify the intensity of the blast pressure at a specific location behind the wall [7], [30]. Rose et al. [7] conducted an experiment study to measure the blast wave parameters behind one-tenth scale of a rigid steel wall [7]. The dimensions of the scaled blast wall model were $300 \mathrm{~mm}$ height, 2,100 mm width, $20 \mathrm{~mm}$ thick. The study found the blast pressure behind the wall at a range of 3 to 6 wall height and was reduced by $60 \%$ to $80 \%$ due to presence of blast wall, respectively as shown in Fig. 6 . Thereafter, the authors extended the study by considering different "limited robustness" blast walls [8]. These are sand, wood, ice, polymeric foam, and water. The authors considered different heights and standoff distances to examine the performance of the walls. The authors represented the scaled peak overpressure and impulse for range of distances behind the considered walls with different heights and thicknesses of the walls. The thick sand wall showed higher capability to attenuate blast pressure behind the wall as shown in Fig. 7. The study confirmed the effectiveness of this type of blast walls to mitigate the explosion impact for non-permanent applications. These studies have focused on measuring the blast pressure behind the walls without focusing on the structural response.

Beyer [30] conducted an experiment to estimate the blast wave parameters of vehicleborne improvised explosive device (VBIED) Beyer's research had led to better understanding of blast environment behind blast wall (see Fig. 8). Through the measurements blast pressuretime of the incident and reflected waves at different distances behind blast walls [31]. 


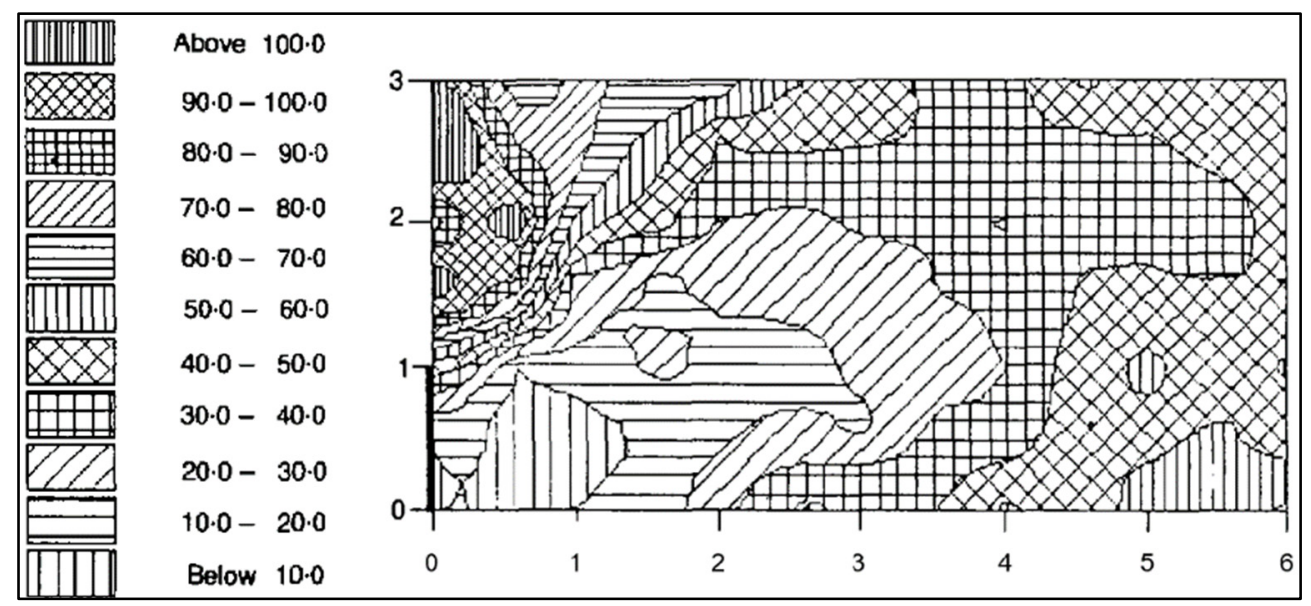

Figure 6: Blast pressure reduction as percentage of pressure without wall [7].

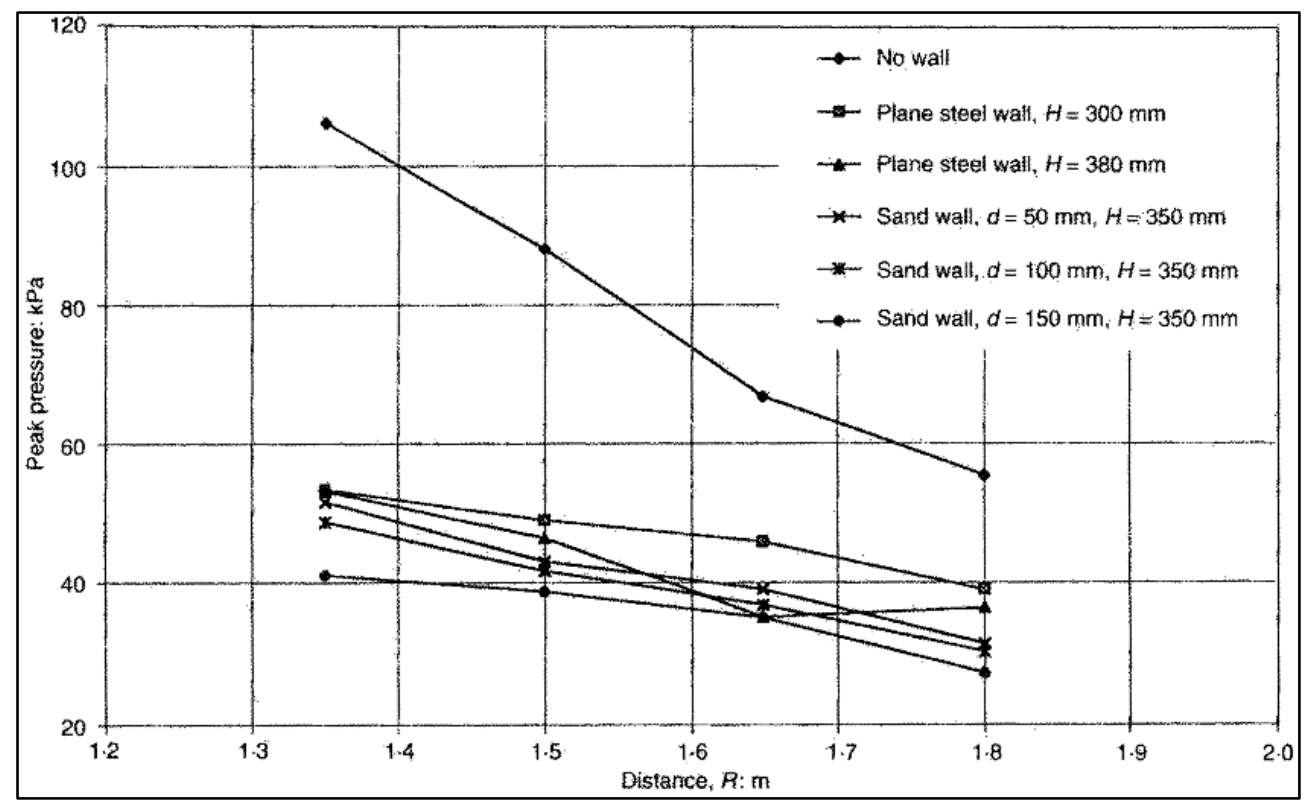

Figure 7: Peak blast pressure behind of plain sand wall with different thicknesses [8].

Rose et al. [32] presented design charts for solid vertical cantilever wall. In these charts, the authors clarified the effect of wall-charge distance, charge height aboveground and wall height on the effectiveness of the blast wall [32]. The charts introduce counters of the distribution of the overpressure and impulse behind the wall. Furthermore, the study showed that adding canopy to the blast wall did not have any significant effects on the reduction factor of the blast pressure behind the wall. 


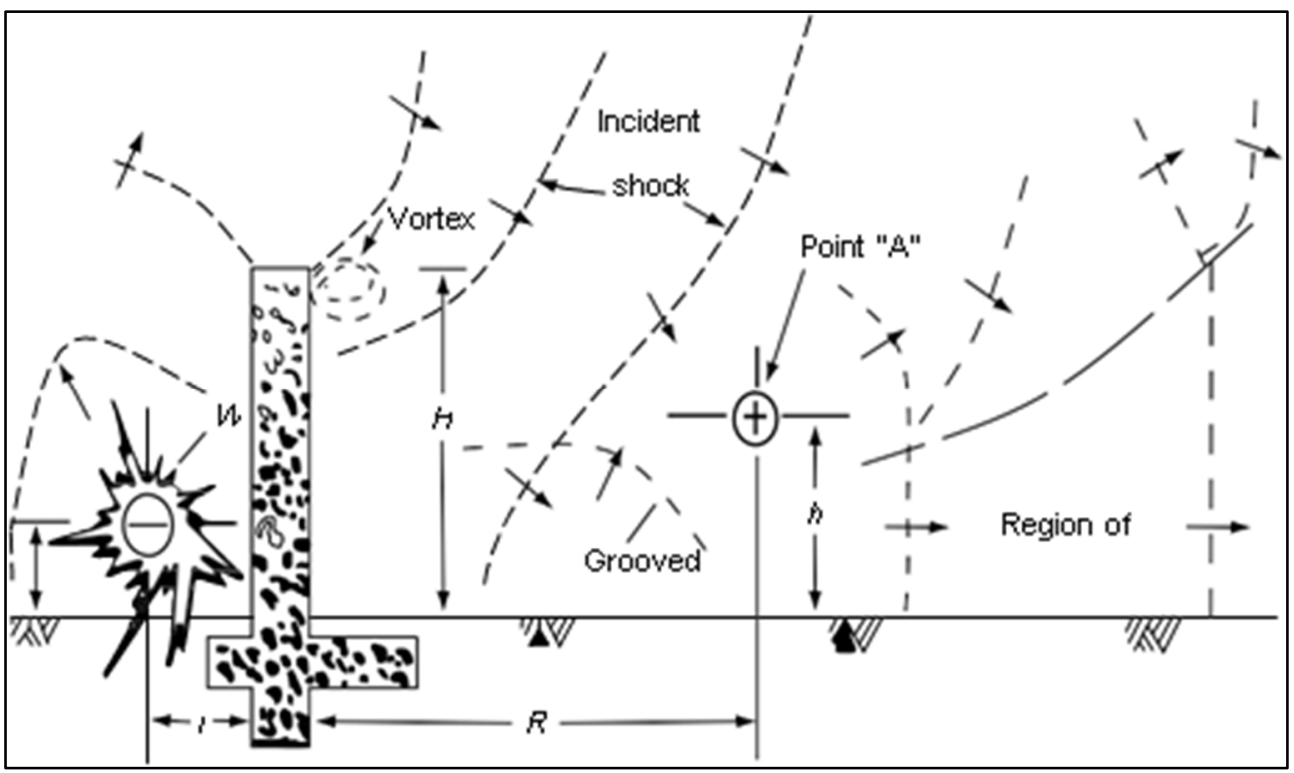

Figure 8: Blast environment behind blast wall [30].

Chapman et al. [33] conducted blast tests to calculate reflected pressure behind 1/10th scaled model of plywood wall. The study calculated the reduction in the reflected pressure as function of scaled distance $(Z)$. The test results clarified the significant of the explosionto-ground height, target height aboveground, and standoff distance from the source of the explosion to the wall on the effectiveness of the blast wall. The authors calculated and presented protection factor as function of the blast load and structure parameters.

Several studies investigated the performance of masonry walls under blast loading. The conducted studies aimed to evaluate the performance of the masonry wall to dissipate the blast energy [34]-[39]. Furthermore, the studies examined the effect of the fracture mechanisms and wall geometry on the distribution of the fragment for prototype and scaled models. Wei and Stewart [34] conducted numerical study to compute the response of unreinforced brick masonry walls under blast loading. The finite element analysis results were compared and validated with blast test data. The authors carried out parametric study to examine the response of the unreinforced brick masonry. The authors stated that thickness of the wall and the boundary conditions had significant role on the blast response. Fig. 9 shows the geometry of the unreinforced masonry wall, and effect of the wall thickness and boundary conditions on the peak blast response. In conclusion, the features, limitations, and current applications of the simple blast wall systems are shown in Fig. 10.

\section{BLAST WALL PROTECTION SYSTEMS-RESEARCH GAP}

The author in this study points out the necessity of using low-cost materials to design blast wall systems for permanent applications. Practically, having a thin sheet of solid plate could save lives and protect structures in different attack scenarios even though the system could experience partial or full fracture. The goal is to attenuate blast energy and reduce peak overpressure and impulse behind the considered blast wall systems since blast shock wave 


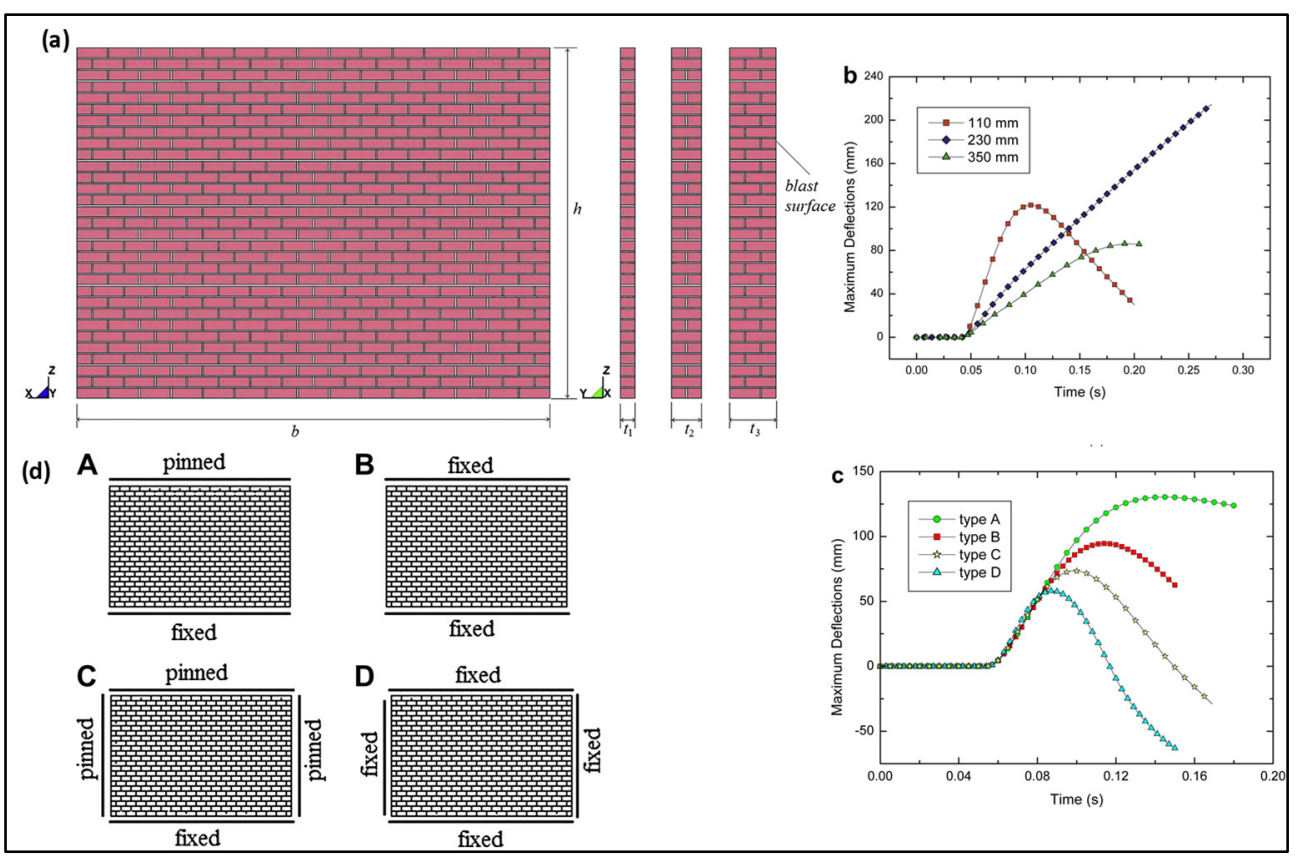

Figure 9: (a) Brick masonry wall; (b) Peak deformation-time of different wall thicknesses $\left(\mathrm{Z}=5.0 \mathrm{~m} / \mathrm{kg}^{1 / 3}\right)$; and (c) Peak deformation-time of different boundary conditions $\left(Z=6.0 \mathrm{~m} / \mathrm{kg}^{1 / 3}\right)$ [34].

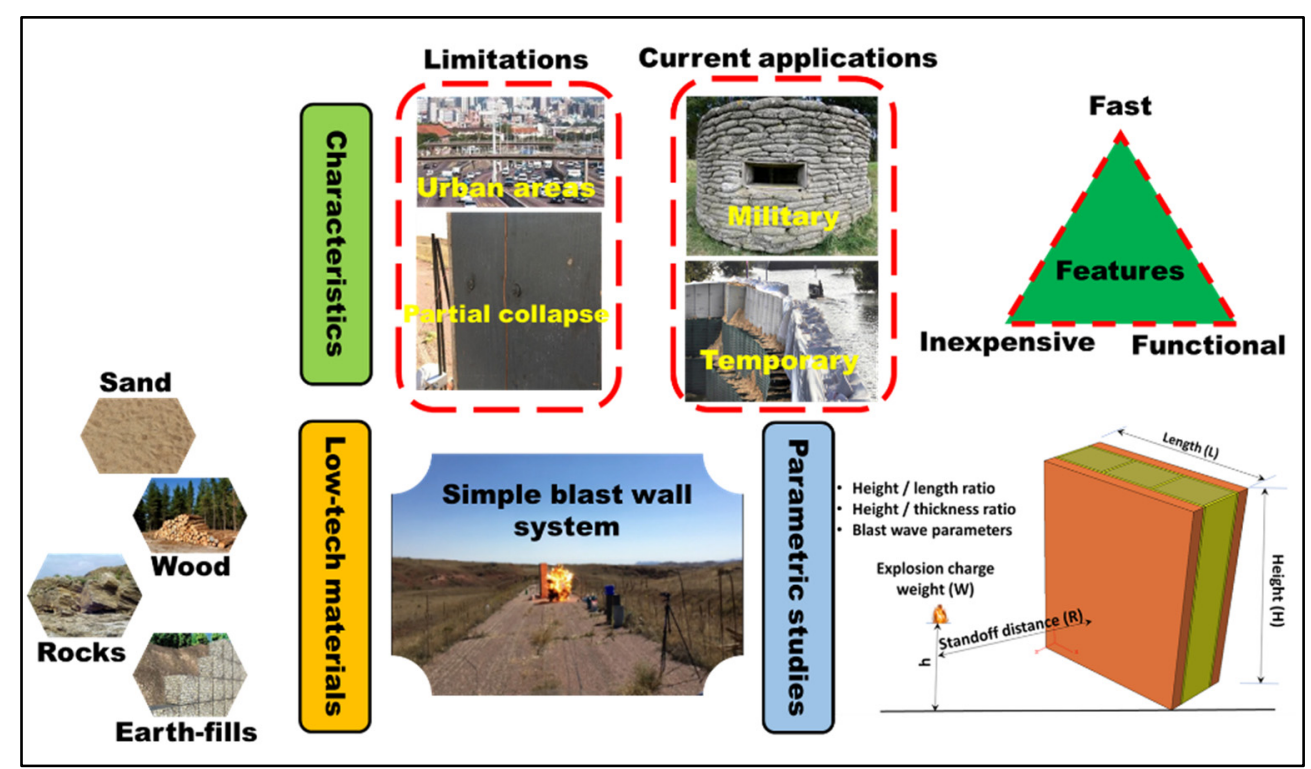

Figure 10: Simple blast wall systems feature, limitations, and current applications. 
pressure is the main blast phenomenon before any other blast phenomena can cause casualties. Simple blast wall systems have been receiving attention from military departments for temporary fortifications. The current study aim is to draw the attention to the benefits of considering simple blast wall systems in urban areas when bombings and suicide attacks threat is probable. The author suggests investigating the performance of low-tech materials which could increase the blast-resistant system efficiency to mitigate the intensity of the blast at almost no cost and minimal efforts. The assessment of the suggested blast wall systems performance could be done through the analysis of the performance of different designs of blast protection wall systems using different approaches, for instance, experimental investigations, analytical techniques and numerical analysis methods, and fragility analysis of prototype systems or equivalent single-degree-of-freedom systems (SDOF). The author presents this research since it is part of a research conducted at Colorado State University (CSU). The author performed open-space blast tests and numerical study to evaluate the performance of oriented strands board (OSB) and Wood-sand-wood (WSaW) blast wall systems [40]. The experimental study objective is to measure blast pressure distribution in front and behind the considered blast walls. The study had tried to answer some questions and concerns about the efficiency of these blast wall systems to mitigate blast since it could be hard to believe that timber and timber-sand blast walls could survive under high-explosive detonations. The outcomes of the study showed that WSaW blast wall had a good capability to mitigate the blast loading. The WSaW blast wall system is shown in Fig. 11. Table 3 shows the reduction percentage $(\phi)$ in the peak overpressure $\left(P_{s o}\right)$ at $60 \mathrm{~cm}$ behind the WSaW wall for range of scaled distances $(Z)$. The open-field blast test results showed the effectiveness of the WSaW wall to mitigate the blast energy. Furthermore, a thin OSB wall reduced the blast peak overpressure by $20 \%$ at $2.44 \mathrm{~m}$ behind the wall. Table 4 shows the reduction percentage in the peak overpressure from placing $9.96 \mathrm{gm}$ of TNT (W) at $2.44 \mathrm{~m}(\mathrm{R})$. The results of the research supported the main idea of this article. That is, it is not necessary to have high-tech sophisticated blast wall systems to mitigate blast loading.

The call to use the simple blast wall systems for permeant applications could initiate a debate inside the engineering community since the idea is still not clear and there are no design specifications yet of this type of blast wall systems for structural protection, therefore, the current study recommends conducting integrated studies to investigate the performance of different simple blast systems and perform architecture design modifications since simple blast wall systems may not be appropriate to install in urban areas. The future studies could investigate and find answers for the following questions: What are the considered hazard scenarios? What are the readily available materials that could be used to mitigate blast loading? What is the safe zone behind /around the suggested blast walls? What is the allowed level of the damage? In conclusion, high-tech blast wall/panel systems have a good capability to resist blast, but most design cases are cost-limited, hence an alternative approach is required. A comparison between the high-tech and simple blast wall systems is summarized in Table 5.

\section{CONCLUSIONS}

The terrorists' strategy has focused on targeting residential and commercial areas where security precautions are not guaranteed to stop the planned attack. Therefore, a reliable blast protection wall system is required to attenuate blast. Simple protection strategies from explosions have been used for military purposes in the last century. The current study focuses on presenting and summarizing the current approach of design blast wall/panel systems and the need to consider an alternative approach using low-tech readily available materials due 

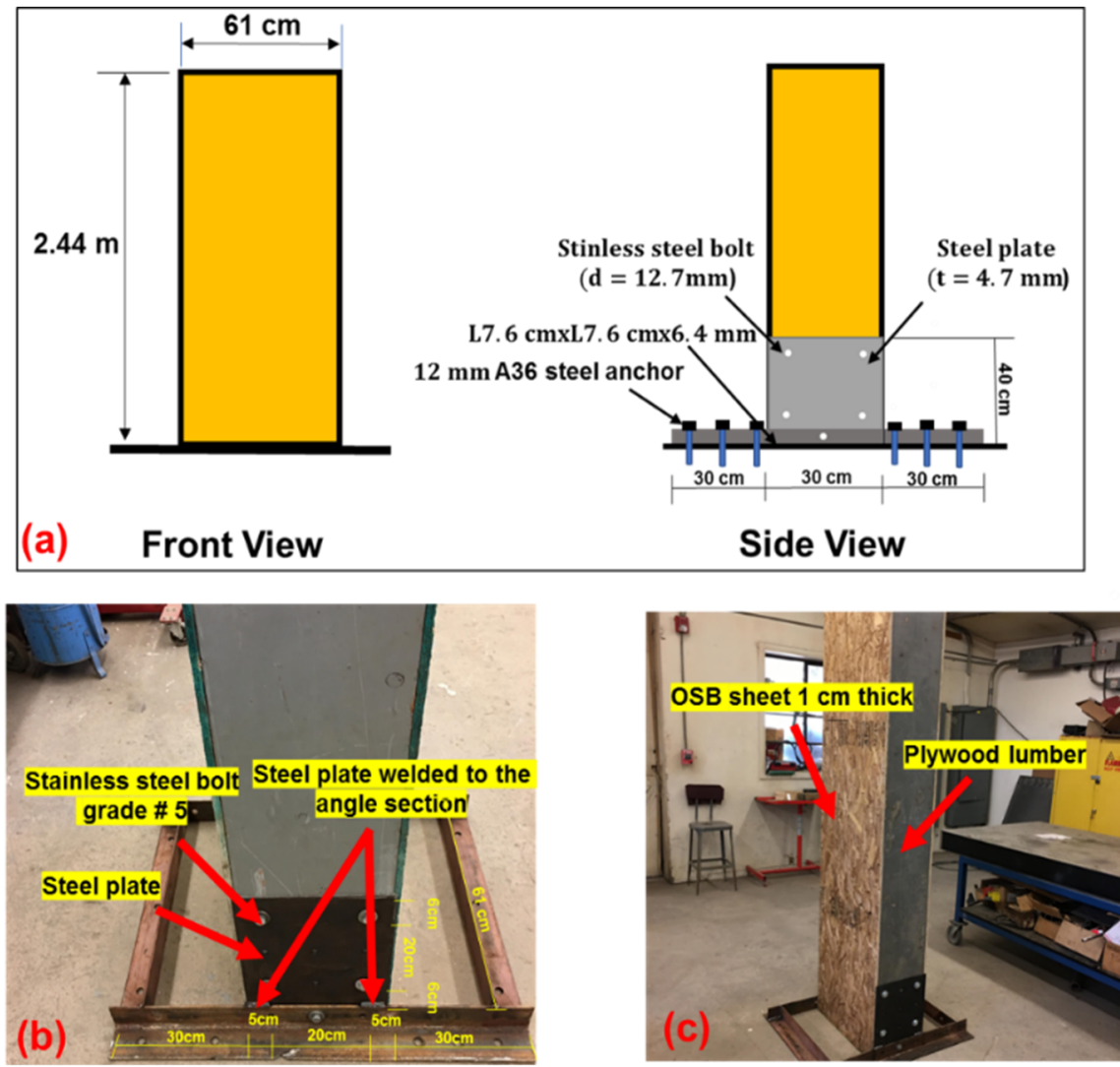

Figure 11: (a) Schematic sketch of the WSaW wall; (b) Connection system details; and (c) Wooden frame details [40].

Table 3: Peak overpressure reduction of WSaW blast wall blast test [40].

\begin{tabular}{|c|c|c|c|c|}
\hline Probe \# & $\begin{array}{c}\mathrm{Z} \\
\left(\mathrm{m} / \mathrm{kg}^{1 / 3}\right)\end{array}$ & $\begin{array}{c}\mathrm{P}_{\text {so }}(\text { Free air }) \\
(\mathrm{kPa})\end{array}$ & $\begin{array}{c}\text { Pso (behind wall) } \\
(\mathrm{kPa})\end{array}$ & $\phi(\%)$ \\
\hline \multirow{6}{*}{$\mathrm{P}_{2}$} & 6.99 & 18.3 & 0.022 & 99.88 \\
\cline { 2 - 5 } & 6.99 & 18.3 & 0.44 & 97.6 \\
\cline { 2 - 5 } & 6.99 & 18.3 & 0.234 & 98.72 \\
\cline { 2 - 5 } & 8.01 & 15.0 & 0.1 & 99.33 \\
\cline { 2 - 5 } & 8.01 & 15.0 & 0.06 & 99.6 \\
\cline { 2 - 5 } & 8.01 & 15.0 & 1.1 & 92.7 \\
\cline { 2 - 5 } & 8.01 & 15.0 & 0.06 & 99.6 \\
\hline
\end{tabular}

Table 4: Peak overpressure reduction of the OSB wall [40].

\begin{tabular}{|c|c|c|c|c|}
\hline $\mathrm{P} \#$ & $\mathrm{R}(\mathrm{m})$ & $\mathrm{W}(\mathrm{gm})$ & $\mathrm{P}_{\mathrm{so}}(\mathrm{kPa})$ & $\phi(\%)$ \\
\hline $\mathrm{P}_{1}$ & 2.44 & 9.96 & 9.26 & \multirow{2}{*}{20} \\
\cline { 1 - 4 } $\mathrm{P}_{2}$ & 2.44 & 9.96 & 11.34 & \\
\hline
\end{tabular}


Table 5: High-tech versus simple blast wall systems.

\begin{tabular}{|c|c|}
\hline High-tech systems & Low-tech systems \\
\hline $\begin{array}{l}\text { Components: } \\
\text { Parent structure } \\
\text { Core structure }\end{array}$ & $\begin{array}{l}\text { Components: } \\
\text { Solid or multi-layers systems }\end{array}$ \\
\hline $\begin{array}{l}\text { Functionality: } \\
\text { Parent structure: Reflector/absorber } \\
\text { Core structure: Absorber }\end{array}$ & $\begin{array}{l}\text { Functionality: } \\
\text { Parent structure: Thin solid plate } \\
\text { Core structure: Thick layer of low-tech } \\
\text { material }\end{array}$ \\
\hline $\begin{array}{l}\text { Characteristics: } \\
\text { Effectiveness: High performance to } \\
\text { resist blast } \\
\text { Application: Limited to important } \\
\text { building } \\
\text { Feasibility: Pricy, need professional } \\
\text { labors and advanced manufacture } \\
\text { techniques }\end{array}$ & $\begin{array}{l}\text { Characteristics: } \\
\text { Effectiveness: Good capability to } \\
\text { mitigate blast } \\
\text { Application: Temporary uses } \\
\text { (currently) } \\
\text { Feasibility: Cheap, easy and fast to } \\
\text { construct and maintain }\end{array}$ \\
\hline
\end{tabular}

to increase in the level of terrorist attacks in last years. This article has highlighted the research gap of the blast wall systems design since only high-tech, sophisticated systems were considered. The study has suggested to adopt a new research trend to mitigate blast shock wave using simple blast wall systems due to the efficiency in mitigating the potential of blast in different attack scenarios. The following conclusions have been summarized according to the findings of this paper.

\subsection{Blast wall systems-limitations and features}

\subsubsection{High-tech blast wall systems}

- Multi-layer systems composed of parent structure made of high ductile materials and low density (high compressible) core structure.

- The function of the front-face sheet is to reflect/absorb most of blast shock wave energy, while the core structure task is to absorb the rest of wave energy.

- The occurrence of permanent deformation in the core structure considers failure to the system.

- The published literature clarified core foam showed higher contribution to dispute blast wave energy comparing to front and back face-sheets.

- Applications of such systems are limited and related to the importance of the structure when permanent deformation is not permissible due to design considerations.

- These blast-resistant wall systems can mitigate blast shock wave effectively, but with the increase of the cost.

\subsubsection{Simple blast wall systems}

- Simple blast walls are inexpensive, easy and fast to construct, easy to maintain, and environmentally friendly, and do not need skilled laborers.

- In general, mass inertia is playing the main role to absorb blast shock wave energy. This very useful and effective alternative to mitigate blast loading comparing to high-tech systems. 
- Partial collapse could be expected, but the required level of protection behind/around blast wall is provided in most attack scenarios.

- Additional integrated studies are required to suggest and investigate the performance of different types of simple blast wall systems.

- This type of blast-resistant wall systems cannot be used in urban areas yet and architecture design modifications need to be considered before it becomes applicable to implement in such areas.

- Most funds have been assigned to military departments. Therefore, efforts should be made to encourage construction companies to support the new applications.

\section{ACKNOWLEDGEMENT}

This work was funded by The Higher Committee For Education Development in Iraq (HCED), and it was been conducted at Colorado State University (CSU). All provided support is really appreciated.

\section{REFERENCES}

[1] Makhutov, A., Petrov, P. \& Reznikov, O., Characteristics of technological terrorism scenarios and impact factors. Countering Terrorism: Biological Agents, Transportation Networks, and Energy Systems: Summary of a US-Russian Workshop, National Academies Press: Washington, DC, pp. 53-69, 2009.

[2] Cernak, I. \& Noble-Haeusslein, L., Traumatic brain injury: An overview of pathobiology with emphasis on military populations. Journal of Cerebral Blood Flow and Metabolism, 30(2), pp. 255-266, 2010.

[3] Bhattacharjee, Y., Shell shock revisited: Solving the puzzle of blast trauma. Science, 319(5862), pp. 406-408, 2008.

[4] Cernak, I., Military-relevant traumatic brain injuries: A pressing research challenge. Johns Hopkins APL Technical Digest, 31(4), pp. 296-300, 2013.

[5] National Institute of Building Sciences, Designing buildings to resist explosive threats. Whole Building Design Guide. www.wbdg.org/resources/designing-buildings-resistexplosive-threats. Accessed on: 16 Apr. 2017.

[6] Koccaz, Z., Sutcu, F. \& Torunbalci, N., Architectural and structural design for blast resistant buildings. Proceeding of the 14th World Conference on Earthquake Engineering, 2008.

[7] Rose, T., Smith, P. \& Mays, G., The effectiveness of walls designed for the protection of structures against airblast from high explosives. Proceedings of the Institution of Civil Engineers: Structures and Buildings, 110(1), pp. 78-85, 1995.

[8] Rose, T., Smith, P. \& Mays, G., Protection of structures against airblast using walls of limited robustness. Proceedings of the Institution of Civil Engineers: Structures and Buildings, 128(2), pp. 167-176, 1998.

[9] Federal Emergency Management Agency, Safe Rooms and Shelters: Protecting People Against Terrorist Attacks, Risk Management Series, 2006.

[10] Shachtman, N., Baghdad "wall”: \$12 Mil (plus bribes). www.wired.com/2007/04/allof-iraq-see. Accessed on: 12 Mar. 2018.

[11] Lee, D., Energy-absorbing sandwich structures under blast loading. Thesis, University of Nevada, Las Vegas, 2004. https://digitalscholarship.unlv.edu/rtds/1687. Accessed on: 8 Jan. 2018.

[12] Dvorak, G. \& Bahei-El-Din, Y., Enhancement of blast resistance of sandwich plates. Proceedings of the 7th International Conference on Sandwich Structures, pp. 107116, 2005. 
[13] Dharmasena, K., Wadley, H., Xue, Z. \& Hutchinson, J., Mechanical response of metallic honeycomb sandwich panel structures to high-intensity dynamic loading. International Journal of Impact Engineering, 35(9), pp. 1063-1074, 2008.

[14] Trasborg, P., Analytical and experimental evaluation of precast sandwich wall panels subjected to blast. Dissertation, Lehigh University, Bethlehem, 2014. https://preserve.lehigh.edu/etd/1656. Accessed on 12 Mar. 2018.

[15] Naito, C., Beacraft, M. \& Hoemann, J., Design limits for precast concrete sandwich walls subjected to external explosions. Proceeding of Structures Congress, ASCE, pp. 1794-1804, 2010.

[16] Liu, X., Tian, X., Lu, J., Zhou, D. \& Liang, B., Blast resistance of sandwich-walled hollow cylinders with graded metallic foam cores. Composite Structures, 94(8), pp. 2485-2493, 2012.

[17] Fatt, S., Gao, Y. \& Sirivolu, D., Foam-core, curved composite sandwich panels under blast. Journal of Sandwich Structures and Materials, 15(3), pp. 261-291, 2013.

[18] Karen, I., Yazici, M. \& Shukla, A., Designing foam filled sandwich panels for blast mitigation using a hybrid evolutionary optimization algorithm. Composite Structures, 158, pp. 72-82, 2016.

[19] Yazici, M., Wright, J., Bertin, D. \& Shukla, A., Experimental and numerical study of foam filled corrugated core steel sandwich structures subjected to blast loading. Composite Structures, 110, pp. 98-109, 2014.

[20] Yazici, M., Wright, J., Bertin, D. \& Shukla, A., Preferentially filled foam core corrugated steel sandwich structures for improved blast performance. Journal of Applied Mechanics, 82(6), pp. 1-13, 2015.

[21] Goel, M., Matsagar, V. \& Gupta, A., Blast resistance of stiffened sandwich panels with closed-cell aluminum foam. Latin American Journal of Solids and Structures, 11(13), pp. 2497-2515, 2014.

[22] Matsagar, V., Comparative performance of composite sandwich panels and noncomposite panels under blast loading. Materials and Structures, 49(1-2), pp. 611-629, 2016.

[23] Ha, J., Yi, H., Choi, J. \& Kim, J., Experimental study on hybrid CFRP-PU strengthening effect on RC panels under blast loading. Composite Structures, 93(8), pp. 2070-2082, 2011.

[24] Hua, Y., Akula, P.P \& Gu, L., Experimental and numerical investigation of carbon fiber sandwich panels subjected to blast loading. Composites Part B: Engineering, 56, pp. $456-463,2014$.

[25] Langdon, G., Karagiozova, D., Theobald, M., Nurick, G., Lu, G. \& Merrett, R., Fracture of aluminium foam core sacrificial cladding subjected to air-blast loading. International Journal of Impact Engineering, 37(6), pp. 638-651, 2014.

[26] Yuen, S. \& Nurick, G., The use of tubular structures as cores for sandwich panels subjected to dynamic and blast loading: A current "state of the art". Blast Mitigation, Springer: London and New York, pp. 229-248, 2014.

[27] Crawford, J. \& Lan, S., Blast barriers design and testing. Proceeding of the 2006 Structural Congress, pp. 1-10, 2006.

[28] US Department of Defense, Structures to resist the effects of accidental explosions. Document No. UFC. 2008:3-40. Unified Facilities Criteria, US Department of Defense, Washington, DC.

[29] Federal Emergency Management Agency, Reference manual to mitigate potential terrorist attacks against buildings, FEMA-426, 2003. 
[30] Beyer, M., Blast loads behind vertical walls. Proceedings of the 22nd Explosives Safety Seminar, Department of Defense Explosives Safety Board, Anaheim, CA, 1986.

[31] Smith, P.D., Blast walls for structural protection against high explosive threats: A review. International Journal of Protective Structures. 1(1), pp. 67-84, 2010.

[32] Rose, T., Smith, P. \& Mays, G., Design charts relating to protection of structures against airblast from high explosives. Proceedings of the Institution of Civil Engineers: Structures and Buildings, 122(2), pp. 186-192, 1997.

[33] Chapman, T., Rose, T. \& Smith, P., Reflected blast wave resultants behind cantilever walls: A new prediction technique. International Journal of Impact Engineering, 16(3), pp. 397-403, 1995.

[34] Wei, X. \& Stewart, M., Model validation and parametric study on the blast response of unreinforced brick masonry walls. International Journal of Impact Engineering, 37(11), pp. 1150-1159, 2010.

[35] Pereira, J., Campos, J. \& Lourenço, P., Experimental study on masonry infill walls under blast loading. Proceeding of 9th International Masonry Conference, pp. 1-9, 2014.

[36] Pandey, A. \& Bisht, R.S., Numerical modelling of infilled clay brick masonry under blast loading. Advances in Structural Engineering, 17(4), pp. 591-606, 2014.

[37] Parisi, F., Balestrieri, C. \& Asprone, D., Blast resistance of tuff stone masonry walls. Engineering Structures, 13, pp. 233-244, 2016.

[38] Shi, Y., Xiong, W., Li, Z. \& Xu, Q., Experimental studies on the local damage and fragments of unreinforced masonry walls under close-in explosions. International Journal of Impact Engineering, 90, pp. 122-131, 2016.

[39] Keys, R. \& Clubley, S., Experimental analysis of debris distribution of masonry panels subjected to long duration blast loading. Engineering Structures, 130, pp. 229-241, 2017.

[40] Hussein, A., Performance assessment of simple blast wall systems. Dissertation, Colorado State University, Fort Collins, 196 pp., 2019. 